\title{
Erratum to: Is there a relationship between dietary MSG and obesity in animals or humans?
}

John T. Brosnan • Adam Drewnowski •

Mark I. Friedman

Published online: 26 July 2014

(C) Springer-Verlag Wien 2014

Erratum to: Amino Acids

DOI 10.1007/s00726-014-1771-6

Unfortunately, the article was published with the incorrect title due to a typesetting error during the production process. The word "and" was omitted between the words "MSG" and "obesity" in the article title. The correct title should read as given below.

Is there a relationship between dietary MSG and obesity in animals or humans?

The online version of the original article can be found under doi:10.1007/s00726-014-1771-6.

J. T. Brosnan $(\bowtie)$

Department of Biochemistry, Memorial University

of Newfoundland, St. John's, NL, A1B 3X9, Canada

e-mail: jbrosnan@mun.ca

A. Drewnowski

Center for Public Health Nutrition, University of Washington,

Seattle, WA, USA

M. I. Friedman

Monell Chemical Senses Center, Philadelphia, PA, USA 